\title{
Experimental and numerical simulation of corrosion induced expansive pressure on concrete cover
}

\author{
Sheikh Shakib ${ }^{a^{*}}$, Abu Zakir Morshed ${ }^{\mathrm{b}}$ and Md. Hasan Ali ${ }^{\mathrm{a}}$
}

${ }^{a}$ Graduate Student, Department of Civil Engineering, Khulna University of Engineering \& Technology, Khulna, Bangladesh ${ }^{b}$ Professor, Department of Civil Engineering, Khulna University of Engineering \& Technology, Khulna, Bangladesh

\begin{tabular}{|c|c|}
\hline C L EI & \multirow{15}{*}{$\begin{array}{l}\text { A B S T R A C T } \\
\text { to evaluate the cracking pressure induced due to corrosion of reinforcement for different cover } \\
\text { thicknesses, grades of concrete and bar locations. The model was also used to determine the } \\
\text { patterns of crack for a different number of bars and the effect of bar diameter on cracking pressure. } \\
\text { The critical pressure was measured experimentally by applying hydraulic pressure through a hole } \\
\text { in concrete cubes of } 150 \mathrm{~mm} \text {. Abaqus } 6.14 \text { was used as a modeling platform. From the } \\
\text { experimentation and numerical modeling, it was found that with the increase of cover thickness } \\
\text { the critical pressure was increased irrespective of bar locations. A lower cracking pressure was } \\
\text { observed for corner bar with respect to the sidebar. On the other hand, with the increase in bar } \\
\text { diameter, a decrease in cracking pressure was observed. The critical pressure observed was also } \\
\text { increased with higher grades of concrete. For corner bars with cover thickness } 37.5 \mathrm{~mm} \text {, the critical } \\
\text { pressure was found as } 6-10 \mathrm{MPa} \text { and it increased up to } 17 \mathrm{MPa} \text { for the cover thickness of } 64 \mathrm{~mm} \\
\text { for different grades of concrete. On the other hand, for other bar location with the cover thickness } \\
\text { of } 37.5 \mathrm{~mm} \text { and } 64 \mathrm{~mm} \text {, the pressure required to initiate crack was about } 7.6 \mathrm{MPa} \text { and } 14.8 \mathrm{MPa} \text {, } \\
\text { respectively, for C } 20 \text { grade concrete. }\end{array}$} \\
\hline Article history: & \\
\hline July, 2019 & \\
\hline 2019 & \\
\hline & \\
\hline & \\
\hline $\begin{array}{l}\text { Neyworas. } \\
\text { Concrete cover }\end{array}$ & \\
\hline Concrete grade & \\
\hline Corrosion & \\
\hline Cracking pressure & \\
\hline & \\
\hline & \\
\hline & \\
\hline & \\
\hline & \\
\hline
\end{tabular}

\section{Introduction}

Concrete is the most versatile material used worldwide to construct various structures like buildings, bridges, highway pavement, and marine structures. Chloride ions present in the marine environment does not affect the concrete but the reinforcement (Neville, 2011). They diffuse into the concrete through the pore spaces and when the amount of chloride ions exceeds a threshold value, it breaks the layer of passivation (Bazant, 1979). This passive layer is formed around the steel bars due to the high alkalinity of the pore solutions (Bazant, 1979). After depassivation of steel, corrosion occurs spontaneously. Corrosion is an electrochemical process in which the steel is oxidized to various stable iron oxides. The volume occupied by the corrosion products is as much as six times the volume of parent metal (Liu \& Weyers, 1998). Initially, a few amounts of corrosion products fill the porous zone of concrete surrounding the reinforcement. So there is no stress developed when free expansion occurs. However, when the volume of the products exceeds that of the porous zone, expansive stress is developed in cover concrete. Thus, as corrosion progresses the volume occupied by the corrosion products accumulating around the reinforcing bar increases. This creates increased pressure on the surrounding concrete. Once * Corresponding author. 
the stress exceeds the tensile strength of concrete, cracking initiates (Bhargava et al. 2006). This pressure needed to initiate crack is defined as a critical pressure. This pressure is important to provide guidelines in sustainable design of reinforced concrete exposed to the marine environment.

In this paper, the pressure needed to crack the concrete cover induced due to corrosion of reinforcement was simulated through experimentation and numerical modeling. In this investigation, the variables were cover thickness, grades of concrete, bar location and bar diameter. Among the variables, the effect of bar diameter was analyzed through numerical modeling only. Uniform corrosion was considered for both experimentation and modeling. On the other hand, initiation and propagation of crack for a different number of bars were analyzed by the model.

\section{Materials and methods}

\subsection{Experimental program}

To measure the critical pressure a cylindrical hole was created to represent reinforcement and hydraulic pressure was applied to simulate the pressure exerted due to corrosion of reinforcement. The critical pressure so found was used to validate the numerical model. Three types of concrete were used in this investigation, C12, C16, C20. ASTM Type I (Ordinary Portland Cement) was used as binder material. River sand having FM of 2.80 was used as fine aggregate and crushed stone of $19 \mathrm{~mm}$ downgrade was used as coarse aggregate. The compressive strength of concrete was tested according to ASTM C39 and the splitting tensile strength test (ASTM C426) was used to measure the tensile strength of concrete. The average 28 days compressive and splitting tensile strengths are shown in Table 1. All the specimens were $150 \mathrm{~mm}$ cubes. Schematic diagram of the specimen is shown in Figure 1. The location of the bars was confirmed by fabricating a $16 \mathrm{~mm}$ diameter plain bar and firmly lubricated so that it can be removed easily leaving a cylindrical hole which was used to simulate corrosion pressure. For the purpose of providing a barrier against leakage through the contact surface of the cylindrical hole and the plate at the bottom surface of the specimens, the hole was $100 \mathrm{~mm}$ in length and a $25 \mathrm{~mm}$ cover was provided. The detailed test program is shown in Table 2. There were two locations of reinforcement chosen to simulate corrosion, one was a sidebar with various clear covers and the other was corner reinforcement with the same clear cover on both side. All the specimens were wet cured and tested after 28 days.

Table 1. Properties of Concrete

\begin{tabular}{lcc}
\hline Grade of Concrete & Avg. Compressive Strength $(\mathrm{MPa})$ & Avg. Splitting Tensile Strength $(\mathrm{MPa})$ \\
\hline C12 & 13.72 & 1.64 \\
C16 & 17.38 & 1.99 \\
C20 & 20.90 & 2.33 \\
\hline
\end{tabular}

Table 2. Test Specimens

\begin{tabular}{llll}
\hline Bar size $(\mathrm{mm})$ & Bar Location & c/d & Concrete types \\
\hline \multirow{2}{*}{16} & Corner $(\mathrm{CB})$ & $2.34,3,4$ & $\mathrm{C} 12, \mathrm{C} 16, \mathrm{C} 20$ \\
& Side (SB) & $2.34,3,4$ & $\mathrm{C} 12, \mathrm{C} 16$ \\
\hline
\end{tabular}

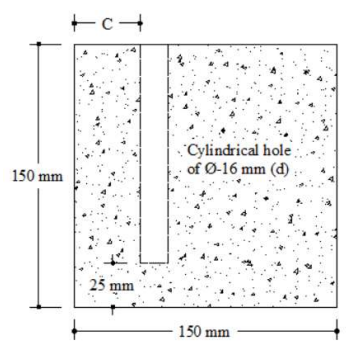

Elevation

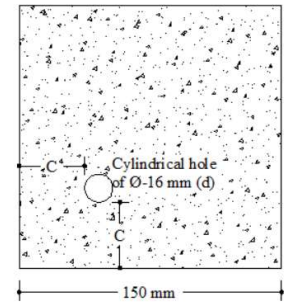

Plan

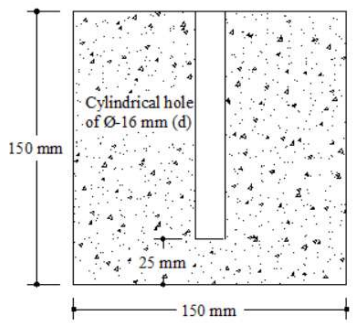

Elevation

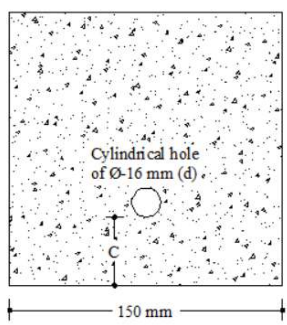

Plan

(a)

(b)

Fig. 1. Schematic Diagrams of Specimens (a) for Corner Bars (b) for Side Bars 
An artificial hydraulic pressure was exerted by a hand pump to represent the uniform corrosion through the hole of the specimens. Due to low compressibility, hydraulic oil was used in the pump. The schematic diagram of the setup is shown in Fig. 2. The end plates were fastened by steel bolt and to resist the longitudinal expansion. A rubber gasket was used at the contact surface of concrete and steel plate. The reason for using the gasket was to make good contact without any damage during fastening and to provide proof against leakage. The pressure was applied at a low rate of approximately $0.5 \mathrm{MPa} / \mathrm{sec}$. At the time of failure, the liquid came out through the cracks and the pressure drops to zero. The peak point of the pressure gauge reading was the critical pressure which criteria was also used by Williamson \& Clark (2000a).

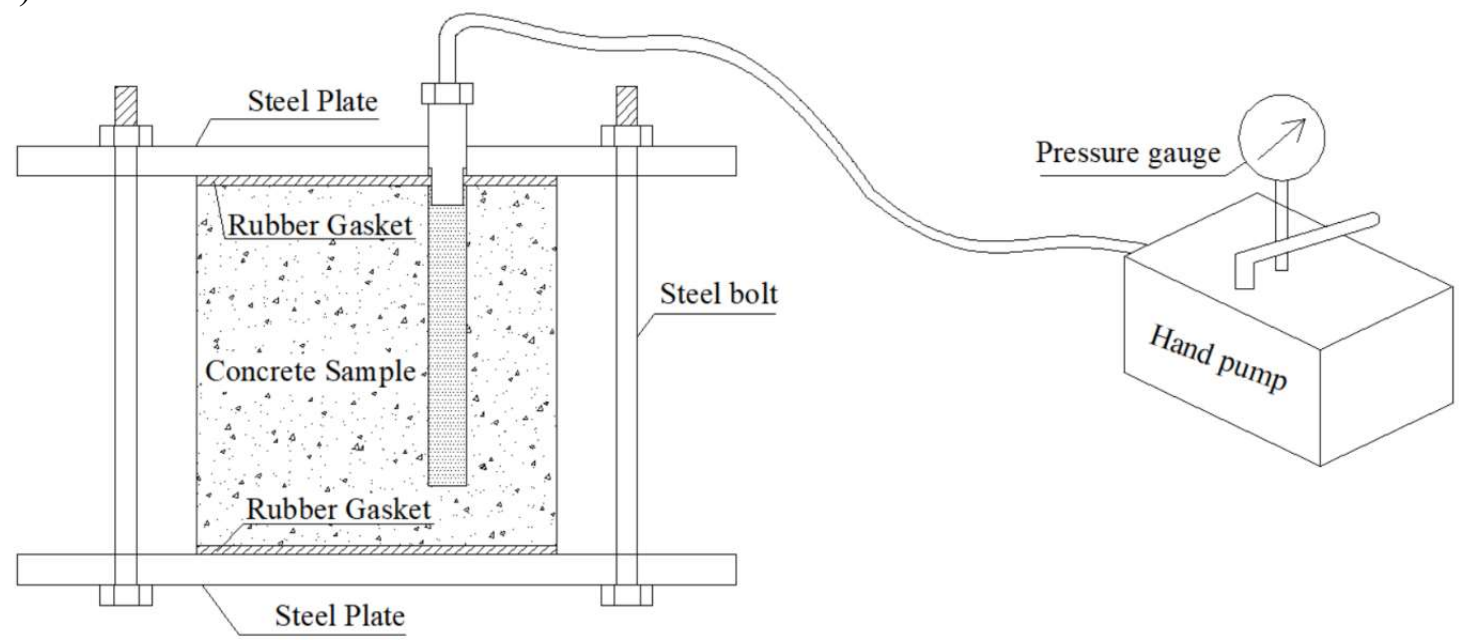

Fig. 2. Schematic Diagram of the Experimental Setup

\subsection{Numerical Modeling}

Commercial software ABAQUS is employed as a modeling platform. The concrete damaged plasticity model, a built-in material model in ABAQUS was used to represent concrete. The elastic part of the material model requires the values of modulus of elasticity and the passion's ratio. The elastic modulus was estimated based on compressive strength given by, ACI 318-02., 2002,

$$
E_{c}=4700 \sqrt{f_{c}^{\prime}} \mathrm{MPa}
$$

where $f_{c}^{\prime}$ is the compressive strength of concrete in MPa which was used similar to that obtained in the experimental study. Poisson's ratio of concrete is usually taken between 0.15 and 0.20 . In the present study, Poisson's ratio is chosen as 0.20 as the concretes used were low-grade concrete. The key aspects of concrete damaged plasticity model are compressive and tensile behavior of concrete, including the damage variable, the yield criterion, the hardening/softening rule, and the flow rule. In this study, the Popovics (1973) model was used to represent stress-strain behavor of concrete in compression.Stressstrain relationship in tensionwas assumed to be linear up to the splitting tensile strength and the stress softening part was determined using the exponential function reported by Dere \& Koroglu, ( 2017).Damage parameters $\left(d_{c}\right.$ and $\left.d_{t}\right)$ were determined based on Lubniner et al.'s (1989) simplified model. Concrete damage plasticity model makes use the Lee \& Fenves, (1998) yield function. To define the yield function two variables were needed to input: one is the ratio of initial equibiaxial compressive yield stress to initial uniaxial compressive yield stress $\left(\sigma_{b 0} / \sigma_{c 0}\right)$ and the other is the ratio of the second stress invariant on the tensile meridian to that on the compressive meridian $\left(K_{c}\right)$. The default values of $\sigma_{b 0} / \sigma_{c 0}=1.16$ and $K_{c}=0.667$ were used. The concrete damaged plasticity model assumes nonassociated potential plastic flow and use the Drucker-Prager hyperbolic function. The defining parameters are dilation angle, $\psi$, and the eccentricity, $\epsilon .30^{\circ}$ was used as dilation angle and the default value of 0.1 was used as ecentricity to define the flow rule in this model. The model geometry and variables were similar 
to that of experimental study as shown in Fig. 3(a) and Fig. 3(b). Since this study focuses on the specimens subject to simulation through hydraulic pressure, in which uniformity of corrosion is considered along the beam length, the 2D simplification is suitable. A 3-node linear plane strain triangle was used as meshing element. The meshing of the model is shown in Fig. 3(c). A sensitivity analysis was done to find out the optimum mesh size. A $0.05 \mathrm{~mm}$ and $0.01 \mathrm{~mm}$ mesh showed similar results and for this reason, $0.05 \mathrm{~mm}$ mesh size was used in this study as an optimized mesh to reduce time consumption. To represent the condition of a real beam, one edge of the model was restrained by implying hinge support as shown in Fig. 3(d). A uniform and gradually increasing outward deformation was applied into the holes to model the expansion induced by corrosion of steel bars. The model was verified through comparison of critical pressure obtained in experimentation.

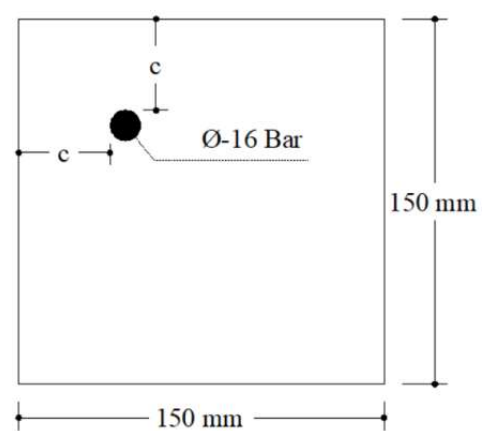

(a)

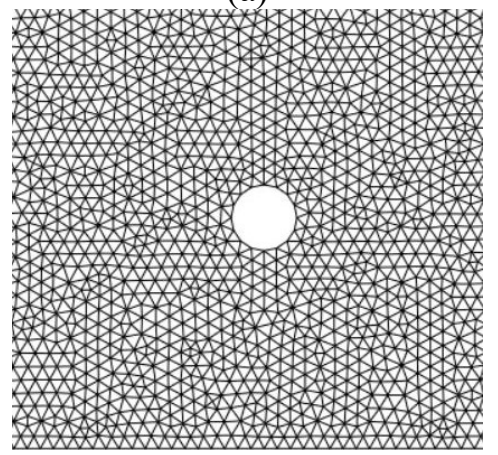

(c)

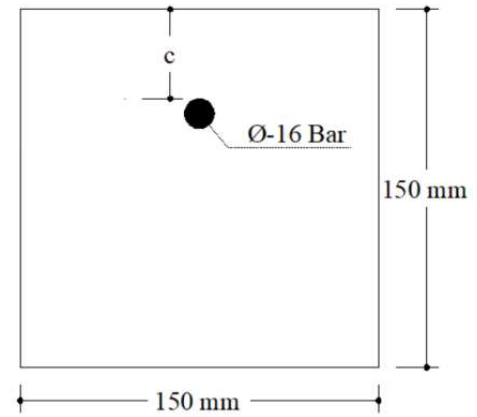

(b)

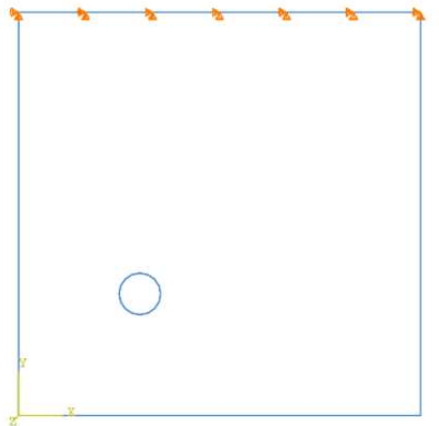

(d)

Fig. 3. Specimens' Dimensions (a) Specimens for Corner Bar (b) Specimens for Side Bar (c) Meshing $\&$ (d) Boundary Condition Applied

\section{Results and discussion}

\subsection{Effect of Concrete Grade}

Critical pressure is dependent on the grades of concrete. The variation of critical pressure with the compressive strength of concretes is shown in Fig. 4. The relationship was built based on compressive strength instead of tensile strength because of the lack of confidence in splitting tensile strength tests. The critical pressure increased with the increase of the strength of concrete. This findings are contradictory with the Williamson \& Clark's (2000) results and agree to the Morinaga's (1988) output. Williamson \& Clark (2000) used the similar specimens but the cover thicknesses were $4 \mathrm{~mm}, 8 \mathrm{~mm}$ and $16 \mathrm{~mm}$ which are very thin compared to the present study $(37.5 \mathrm{~mm}, 48 \mathrm{~mm}$ and $64 \mathrm{~mm})$. Whereas a cylindrical specimen with a hole at the center was used in Morinaga's (1988) experiment. As the tensile strength increases with the increase in compressive strength (Nevile), it is obvious that tensile strength affects the critical pressure. On the other hand, the tensile strength is the governing factor in yield criteria to explain the failure of concrete. In the numerical simulation fracture of concrete was based on yield 
criteria. And a similar patterns were observed from the finite element analysis as shown in Figure 5. There was a good agreement between the experimental and numerical results as the variation lied below $30 \%$. So it may conclude that the concrete grade is an influencing factor in simulating the critical pressure.

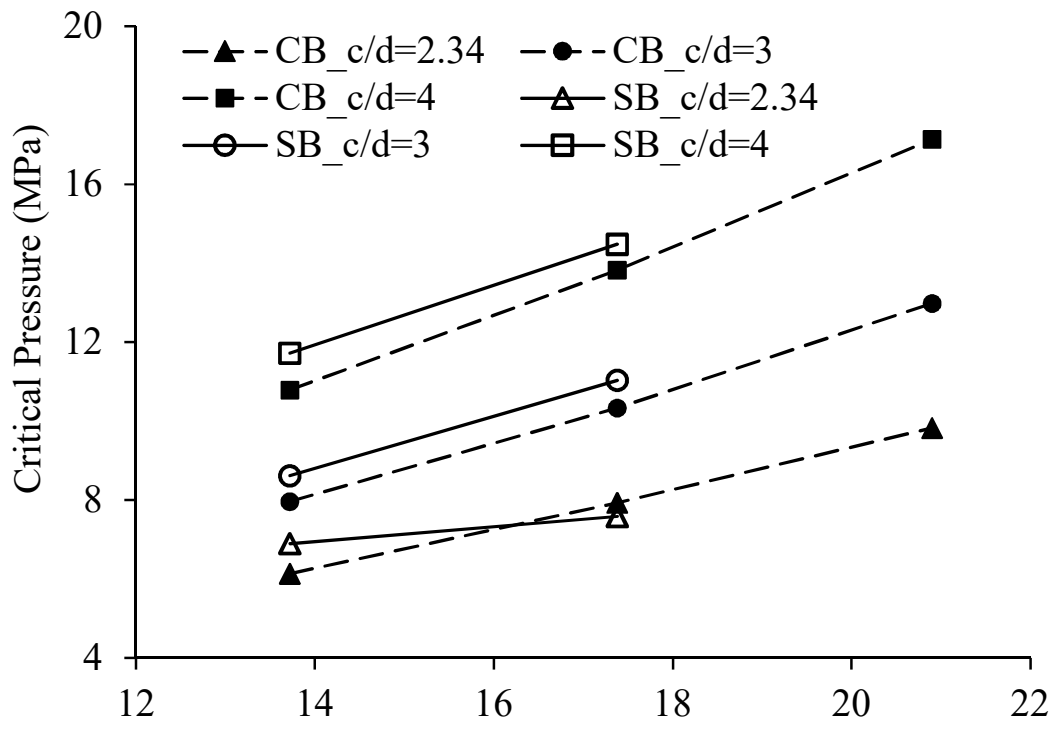

Compressive Strngth of Cocrete (MPa)

Fig. 4. Variation of Critical Pressure Observed in Experimentation with the concrete grades

\subsection{Effect of Concrete Cover}

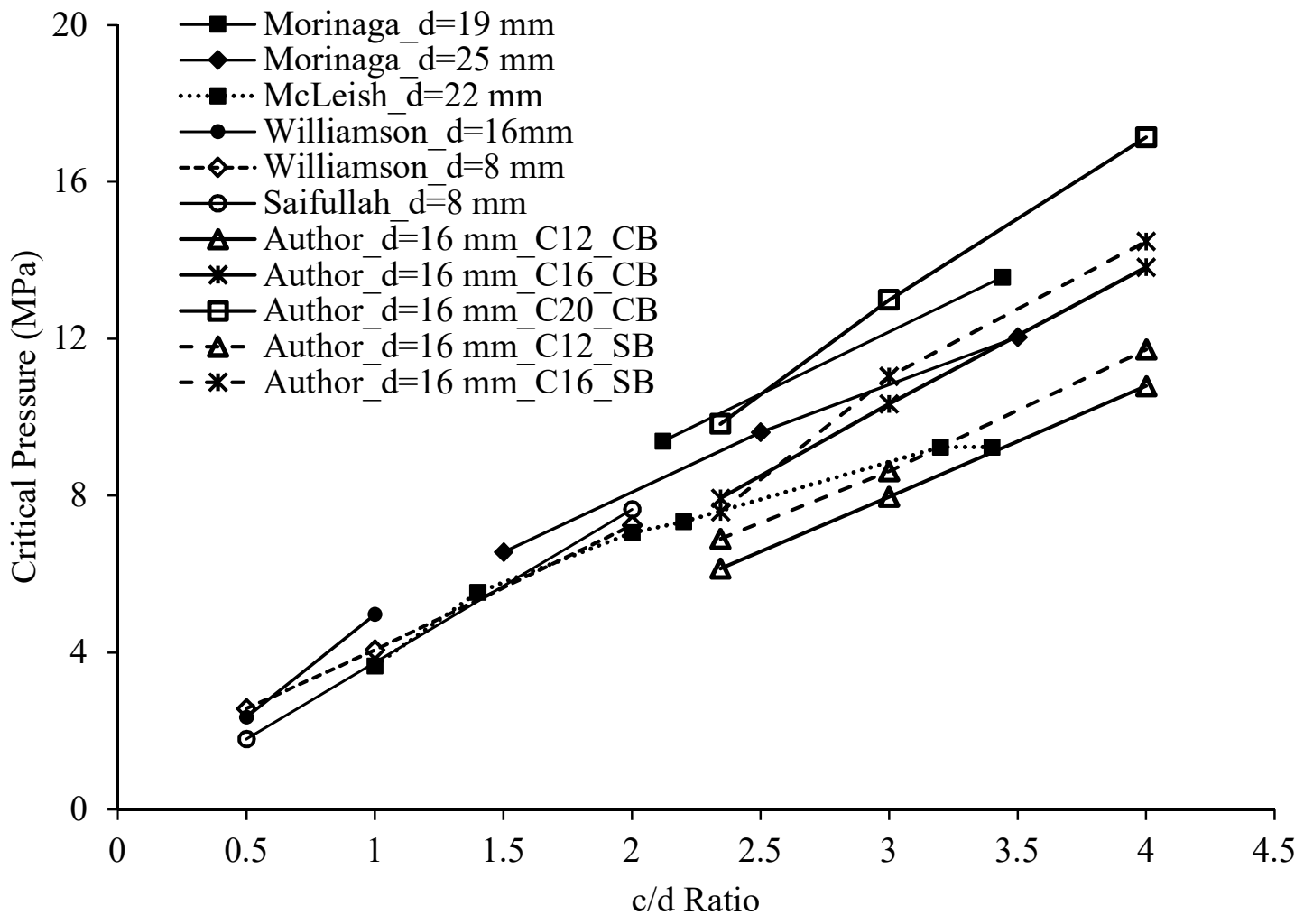

Fig. 5. Variation of Critical Pressure Observed in Experimentation with the c/d Ratio along with the Comparisonto Other Researchers (Reproduced fromWilliamson \& Clark, 2000). 
The results of experiment and the variation with the numerical ones are shown in Fig. 4 and Fig. 5. Fig. 4 shows the results for side bars and Fig. 5 shows the results for corner bars. The pressure needed to initiate crack, known as critical pressure, was increased for increasing both the clear cover and grade of concrete. Numerical results showed the same patterns. The agreement of numerical results with the experimental ones are given in Table 3. The percent variation of critical pressure differed from 12 to $30 \%$. The cracking of concrete was mainly dependent on the tensile strength of concrete. Tensile strength of concrete very much dependent on the method of testing (Val et al., 2009). In the experimental works, the splitting tensile strength was used and the results was also employed in the Finite Element analysis. Whereas in the Finite Element analysis, based on Rankine's criteria, the direct tensile strength was appropriate (Val et al., 2009). The variation of the results might be due to the differences in the boundary conditions between the experiment and numerical model. In the experimental investigations, only plain strain condition was maintained and the edges were kept in free. Whereas in the modeling, single edge was restrained against horizontal and vertical movement which is similar to that of real beams.

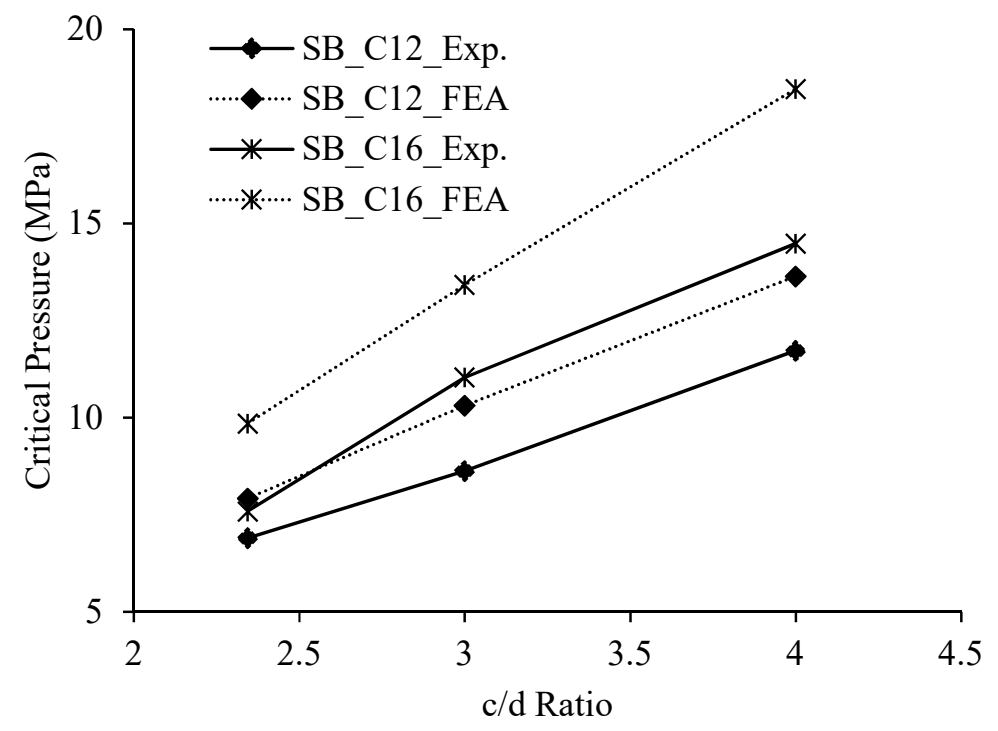

Fig. 4. Comparison of Failure Pressures Obtained from Experiment and Finite Element Analysis for Side Bars

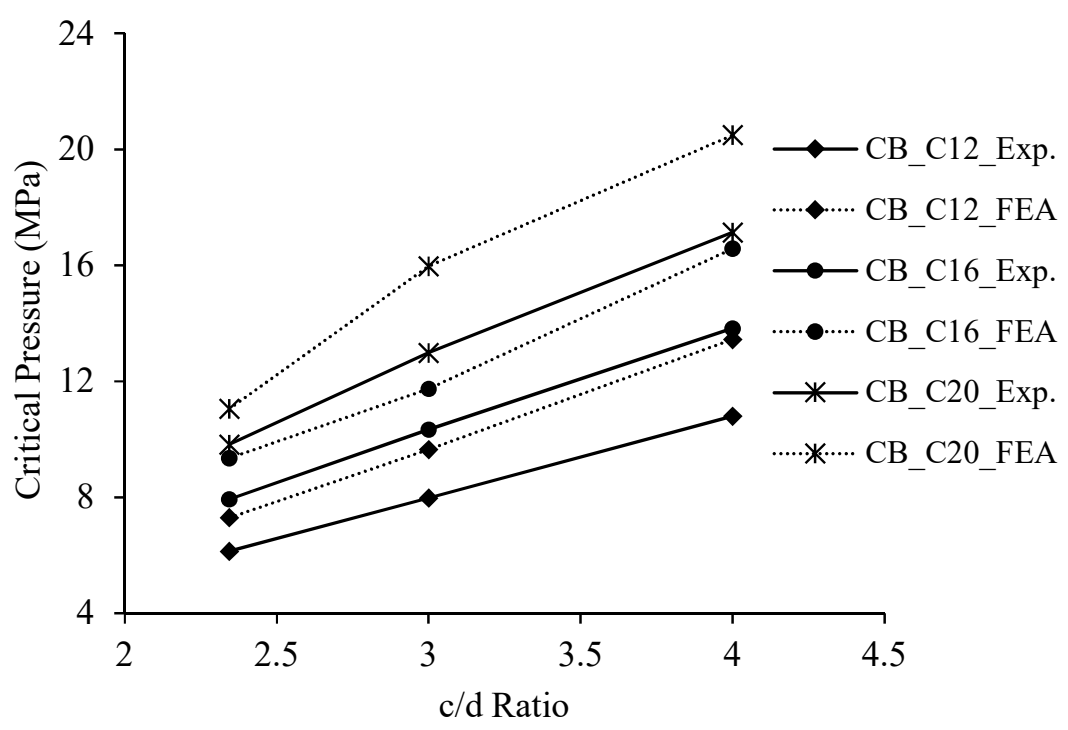

Fig. 5. Comparison of Failure Pressures Obtained from Experiment and Finite Element Analysis for Corner Bars 
Both the experimental and the finite element results showed a gradual increase in critical pressure with the increase in strength of concrete which is contradictory with the previous one(Williamson \& Clark, 2000).Previous study showed that no dependency of the critical pressure was found on the grade of concrete. Since the critical pressure is very much dependent on the tensile strength of concrete, the dependency on the grade of concrete is obvious.

Table 3. Percent Variation of Critical Pressure from Finite Element Analysis (FEA) With the Experimental Ones

\begin{tabular}{cccccc}
\hline \multirow{2}{*}{$\begin{array}{c}\text { Clear cover } \\
(\mathrm{mm})\end{array}$} & \multicolumn{2}{c}{ For Corner Bar $(\mathrm{CB})(\%)$} & \multicolumn{2}{c}{ For Side Bar (SB) (\%) } \\
\cline { 2 - 6 } & $\mathrm{C} 12$ & $\mathrm{C} 16$ & $\mathrm{C} 20$ & $\mathrm{C} 12$ & $\mathrm{C} 16$ \\
\hline 37.5 & 18.8 & 17.8 & 12.4 & 14.8 & 29.8 \\
48 & 21.1 & 13.7 & 22.9 & 19.6 & 21.6 \\
64 & 24.6 & 19.9 & 19.6 & 16.4 & 27.5 \\
\hline
\end{tabular}

\subsection{Effect of bar location}

In Fig. 6 the critical pressures for corner bars were plotted with respect to that of side bars to evaluate the effect of bar location. Fig. 6 shows that the experimental results were very close to the line of equality for all grade of concrete whereas the results from finite element results for the higher grade of concrete shows a lower critical pressure for corner bars. And this effect prolonged for higher $\mathrm{c} / \mathrm{d}$ ratio. This might be due to,for larger the diameter of bar, cover concrete for corner reinforcement was more fragile than an equal thickness of cover for a side bar (Williamson \& Clark, 2000). A similar pattern was also found in past studies which showed that several specimens with corner reinforcement failed at lower pressures than the specimens with side bar (Allan \& Cherry, 1992).

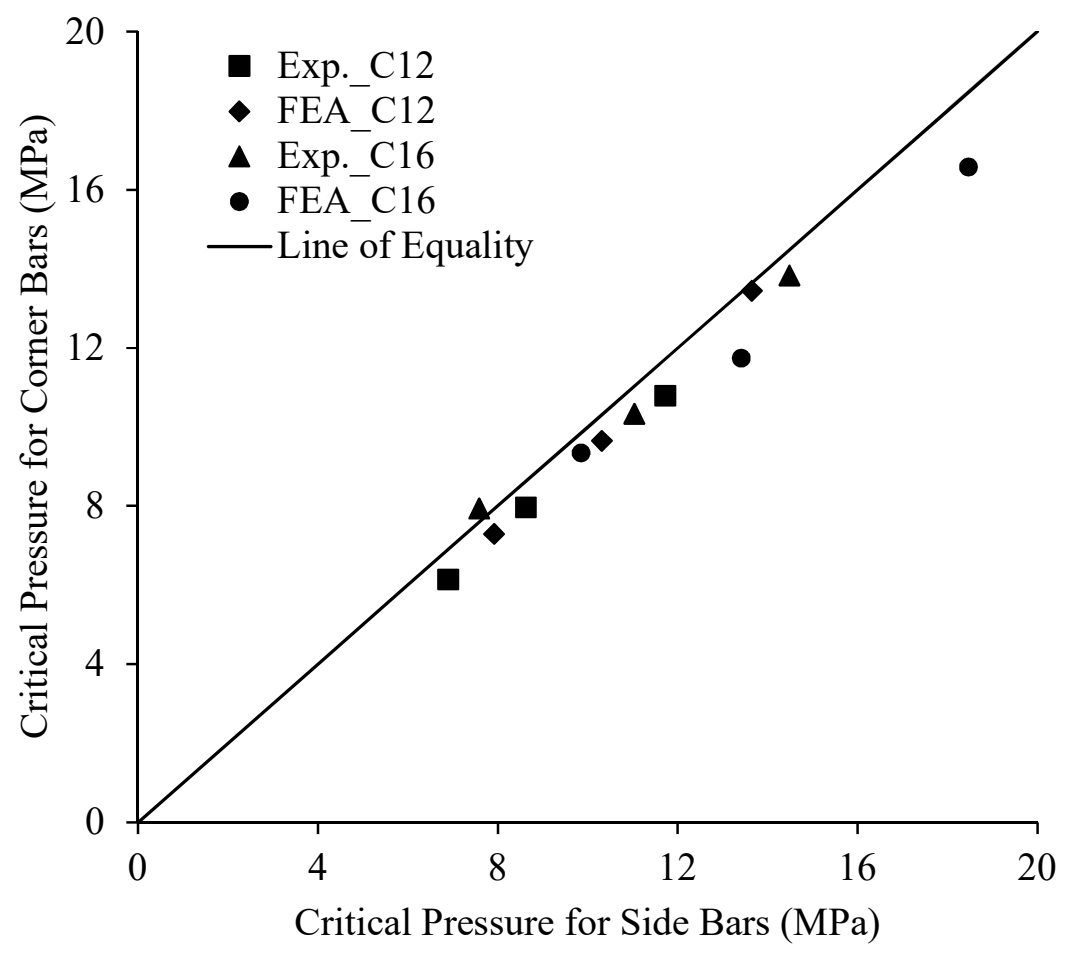

Fig. 6. Effect of Bar Location on Failure Pressure

The radial deformations needed to crack the concrete cover is plotted in Fig. 7 to evaluate the effect of bar location. The radial deformations could not be measured in the experimentation so only the numerical results are shown in Figure. The figure showed a similar pattern as for pressure shown in Figure 6. For higher cover to diameter ratio a lower expansion was needed for corner bar. 


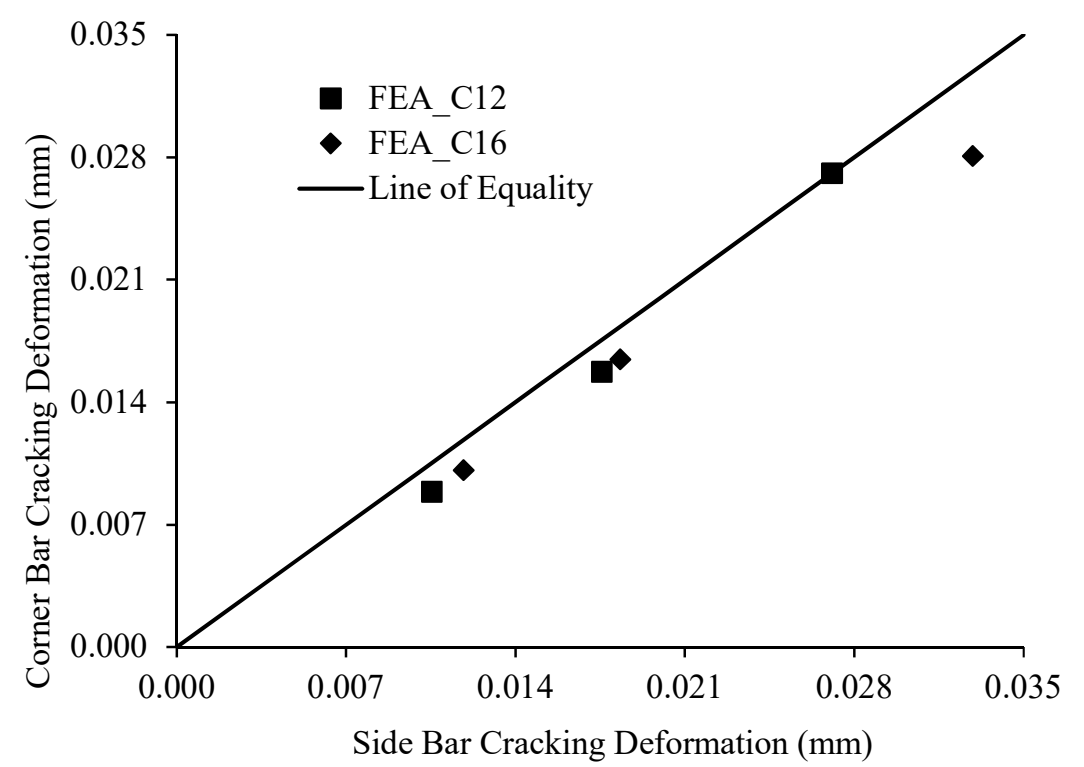

Fig. 7. Effect of Bar Location on Radial Expansion

\subsection{Effect of bar size}

Five finite element models were developed with varying hole diameters (d), from $10 \mathrm{~mm}$ to $25 \mathrm{~mm}$, where all other geometric and material properties were kept constant $(\mathrm{C}=48 \mathrm{~mm}$, Grade of concrete, C20). The pressure required for cracking of the concrete cover for each model is shown in Figure 8. Figure 8 shows that the expansive pressure decreased with the increase in bar diameter. By increasing the bar diameter, the lateral surface of the hole increased which results in higher outward force and consequently lower required pressure for the cracking. On the other hand for the same cover thickness, if the bar diameter was increased, the cover of smaller diameter was stiffer than that of larger diameter (Williamson \& Clark, 2000). It is obvious that the greater the bar diameter, the larger the loading surface area so that there is more probability to find a weak point in the larger diameter. Williamson \& Clark (Williamson \& Clark, 2000) also found a reduction of about $20 \%$ in pressure for doubling the bar diameter from $8 \mathrm{~mm}$ to $16 \mathrm{~mm}$.

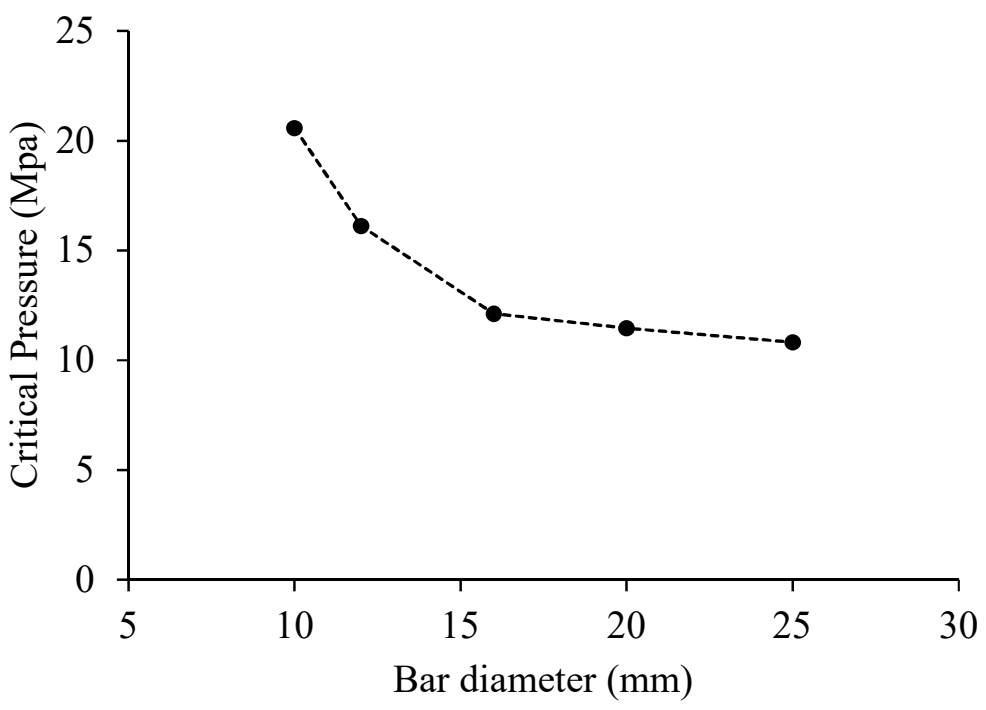

Fig. 8. Effect of Bar Diameter on the Required Pressure for Cracking 


\section{Application of models to real beams}

The model was applied to predict the cracking of cover concrete in a real beam specimen having a cross section of $300 \mathrm{~mm} \times 500 \mathrm{~mm}$. Reinforcement bars were arranged in different configuration for a cover thickness (C) of $37.5 \mathrm{~mm}$.

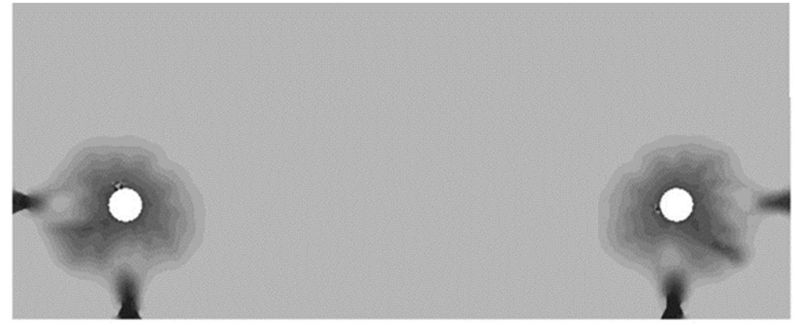

(a)

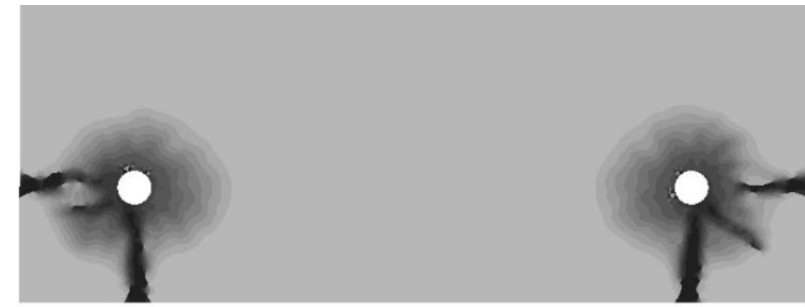

(b)

Fig. 9. (a) Initiation and (b) Propagation of Cracks for 2-12 $\mathrm{mm}$ bar

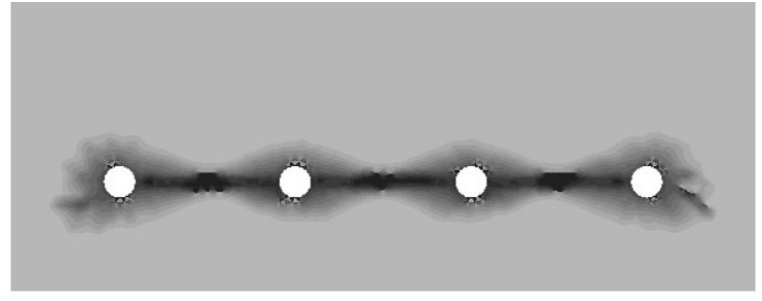

(a)

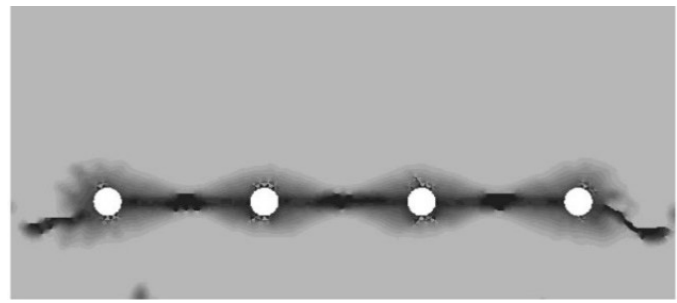

(b)

Fig. 10. (a) Initiation and (b) Propagation of Cracks for 4-12 mm bar

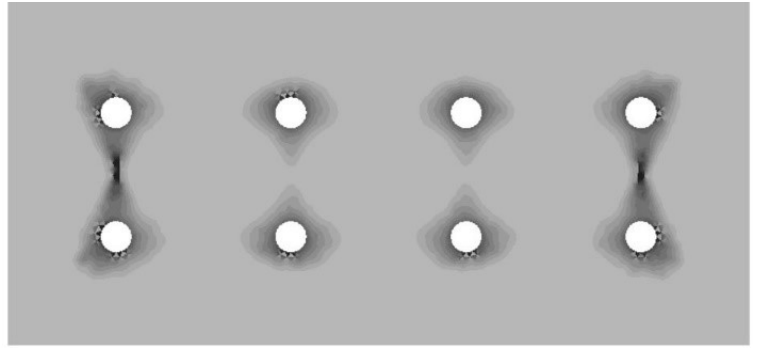

(a)

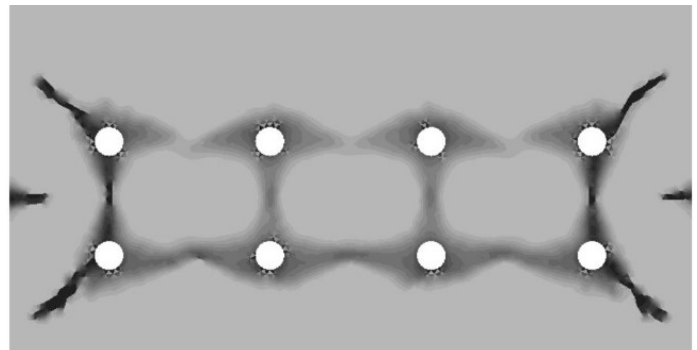

(b)

Fig. 11. (a) Initiation and (b) Propagation of Cracks for 8-12 $\mathrm{mm}$ bar

Cracking initiation and propagation pattern of different configurations with 2, 4 \& 8-12 $\mathrm{mm}$ diameter plain bar are shown in Fig. 9 to Fig. 11. When number of bars were two, then cracking at corner and spalling was occurred which is shown in Fig. 9. Whereas for number of bars increased to four and 8, an internal initiation of crack was observed and propagated towards the cover surfaces leading to spalling as shown in Fig. 9 and Fig. 10. As a lower area was found to be resolved the pressure induced due to corrosion in case of higher number of reinforcement. In this investigation all the reinforcement were considered as uniformly corroding. So where a series of reinforcement are corroded at a time like slab, foundation, beam with higher reinforcement ratio etc. there is a possibility to crack internally and leads to spall away rather than cracking a certain point.

\section{Conclusion}

From the experimental simulation of the critical pressure for cover cracking it was found that the critical pressure was very much dependent on the cover thickness, grade of concrete and location of the 
bar. The greater the cover thickness the greater the cracking pressure. It was also found that, a greater pressure was needed when a higher grade of concrete was used. On the other hand, for corner bars a lower pressure was needed to crack with respect to the side bars. A numerical model was developed to predict the pressure and radial expansion induced due to corrosion products. The model predicted the critical pressure with a reasonable accuracy as compared with the experimental investigations. The model successfully predicted the patterns of cracks due to uniform corrosion for group of bars. Critical pressure and the radial expansion induced due to expansive corrosion products were found to be affected by cover thickness, grade of concrete, location of bar and diameter of bar. With the increase in cover thickness the pressure as well as the radial expansion needed to initiate crack was increased. On the other hand, with the increase in bar diameter a decrease in critical pressure was observed.

\section{References}

Allan, M. L., \& Cherry, B. W. (1992). Factors controlling the amount of corrosion for cracking in reinforced concrete. Corrosion, 48(5), 426-430.

Bazant, Z. P. (1979). Physical Model for Steel Corrosion in Concrete Sea Structures - Theory. Journal of the Structural Division-ASCE, 105(6), 1137-1153.

Bhargava, K., Ghosh, A. K., Mori, Y., \& Ramanujam, S. (2006). Model for cover cracking due to rebar corrosion in RC structures. Engineering Structures, 28(8), 1093-1109.

Dere, Y., \& Koroglu, M. A. (2017). Nonlinear FE modeling of reinforced concrete. International Journal of Structure in Civil Engineering Resources, 6(1), 71-74.

Lee, J., \& Fenves, G. L. (1998). Plastic-damage model for cyclic loading of concrete structures. Journal of Engineering Mechanics, 124(8), 892-900.

Liu, Y., \& Weyers, R. E. (1998). Modeling the time-to-corrosion cracking in chloride contaminated reinforced concrete structures. ACI Materials Journal, 95(6), 675-680.

Lubliner, J., Oliver, J., Oller, S., \& Oñate, E. (1989). A plastic-damage model for concrete. International Journal of Solids and Structures, 25(3), 299-326.

Neville, A. M. (2011). Properties of concrete (5th Edition). England, Pearson Education Limited.

Popovics, S. (1973). A numerical approach to the complete stress-strain curve of concrete. Cement and Concrete Research, 3(5), 583-599.

Val, D. V., Chernin, L., \& Stewart, M. G. (2009). Experimental and Numerical Investigation of Corrosion-Induced Cover Cracking in Reinforced Concrete Structures. Journal of Structural Engineering, 135(4), 376-385.

Williamson, S. J., \& Clark, L. A. (2000). Pressure required to cause cover cracking of concrete due to reinforcement corrosion. Magazine of Concrete Research, 52(6), 455-467.

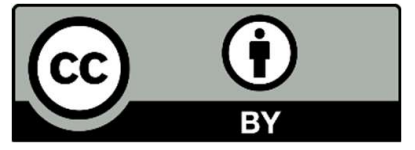

(C) 2020 by the authors; licensee Growing Science, Canada. This is an open access article distributed under the terms and conditions of the Creative Commons Attribution (CC-BY) license (http://creativecommons.org/licenses/by/4.0/). 